\title{
DESAFIOS DA EDUCAÇÃO AMBIENTAL CRÍTICA EM ESCOLAS PÚBLICAS DE MOSSORÓ (RN)
}

\author{
João Paulo Pereira Rebouças ${ }^{1}$ \\ Gustavo Ferreira da Costa Lima² \\ Edevaldo da Silva ${ }^{3}$
}

Resumo: Esta pesquisa analisou a dinâmica do processo pedagógico de escolas de ensino básico no município de Mossoró, Rio Grande do Norte, quanto ao desenvolvimento da Educação Ambiental (EA) crítica. A análise abrangeu três dimensões: o projeto político-pedagógico (PPP), o currículo e a prática pedagógica. A metodologia possui abordagem qualitativa, utilizando para a coleta de dados a revisão bibliográfica, a pesquisa documental, a observação e os grupos focais com roteiros semiestruturados. Os resultados revelaram que os princípios e diretrizes da EA crítica vão gradualmente se diluindo e perdendo sua potência transformadora e emancipatória à medida que o processo pedagógico se desenvolve do PPP até a prática pedagógica.

Palavras-chave: Educação Ambiental Crítica; Processo Pedagógico; Emancipação Social.

Abstract: This research analyzed the dynamics of the pedagogical process in elementary schools in the municipality of Mossoró, Rio Grande do Norte, regarding the development of critical environmental education (EE). The analysis covered three dimensions: the political-pedagogical project (PPP), the curriculum and pedagogical practice. The methodology has a qualitative approach, using bibliographic review, documentary research, observation and focus groups with semi-structured scripts for data collection. The results revealed that the critical EA principles and guidelines are gradually being diluted and losing their transformative and emancipatory power as the pedagogical process develops from the PPP to the pedagogical practice.

Keywords: Critical Environmental Education; Pedagogical Process; Social Emancipation.

\footnotetext{
${ }^{1}$ Instituto Federal de Educação, Ciência e Tecnologia do Maranhão. E-mail: joao.reboucas@ifma.edu.br. Link para o Lattes: http://lattes.cnpq.br/5302548259517783

2 Universidade Federal da Paraíba. E-mail: gust3lima@uol.com.br.

Link para o Lattes: http://lattes.cnpq.br/8153297424559789

${ }^{3}$ Universidade Federal de Campina Grande. E-mail: edevaldos@yahoo.com.br. Link para o Lattes: http://lattes.cnpq.br/4787607680301269
} 


\section{Introdução}

A evolução histórica da questão ambiental global, nas últimas décadas, tem sido marcada pelo agravamento da degradação da biosfera e das mudanças climáticas globais, resultantes de um modelo de desenvolvimento predatório e insustentável. No plano nacional, verificam-se graves retrocessos institucionais, falta de prioridade política e de decisão de pôr em prática um projeto democrático de sustentabilidade (ROCKSTRÖM, 2009; BURSZTYN; BURSZTYN, 2012). A marca que o ser humano imprime na natureza desde a Revolução Industrial é tão intensa que alguns analistas, dentre eles Crutzen (2002), têm proposto a hipótese Antropoceno, como uma nova era geológica. Ou seja, argumentam que a presença humana na Terra se transformou em uma força geológica sistêmica que tem impactado e modificado, não apenas a biosfera, mas também a litosfera, a hidrosfera e a atmosfera terrestres. Outro grupo de analistas, ainda que reconheçam a relevância do debate sobre o Antropoceno, entende que ele é impreciso e injusto pela responsabilização genérica de toda a espécie Antropos e prefere substituí-lo por Capitaloceno, para evocar a responsabilidade de um modo de produção e desenvolvimento (KLEIN, 2014; MOORE, 2016).

A Educação Ambiental (EA) como instrumento de formação cultural indispensável para a proteção e melhoria das condições ambientais está posta na agenda política internacional desde a Declaração de Estocolmo de 1972. No Brasil, a EA alcança o status de Política Nacional no final da década de 1990, definida no Art. $1^{\circ}$ pelas relações estabelecidas entre 0 indivíduo e a coletividade que "constroem valores sociais, conhecimentos, habilidades, atitudes e competências voltadas para a conservação do meio ambiente, bem de uso comum do povo, essencial à sadia qualidade de vida e sua sustentabilidade", bem como sua inserção no processo educativo de forma permanente e capilarizada em todos os níveis e modalidades do ensino, seja no espaço formal ou fora dele (BRASIL, 1999).

Importante pontuar que a EA não possui uma definição única. É, ao contrário, um termo polissêmico que expressa vários significados por ser uma práxis decorrente de um campo teórico e prático em disputa (LAYRARGUES, 2004; SAUVÉ, 2005; LIMA, 2011), em que diferentes abordagens pedagógicas, epistemológicas e políticas coexistem (REIBELT et al., 2014). Isso quer dizer que as práticas de Educação Ambiental estão disseminadas pelo país e pelo mundo com diferentes orientações teóricas e metodológicas. Neste sentido, uma de suas correntes, a Educação Ambiental identificada com raízes emancipatórias e críticas, que a literatura convencionou chamar de EA crítica, apresenta-se com um perfil conceitual próprio (LIMA, 2011).

Diante dos problemas ambientais que desafiam as sociedades no início deste século, muitos deles de caráter complexo e multidimensional, coloca-se a necessidade de construir um processo pedagógico que não perca de vista a totalidade, suas partes e inter-relações recíprocas. Esse olhar amplo da realidade é um dos componentes que caracterizam a EA crítica e modulam 
seus projetos pedagógicos (RODRIGUES; LOUREIRO, 2017; GUIMARÃES, 2018). A abordagem complexa se justifica pela necessidade de problematizar a realidade e refletir sobre ela, não se satisfazendo com simplificações e reducionismos. Exige, ao contrário, um conhecimento interdisciplinar e o diálogo entre as disciplinas e diferentes saberes. Neste sentido, importa adotar uma análise multidimensional dos problemas e suas relações a partir das diversas perspectivas da realidade, social, cultural, ética, econômica, histórica, ecológica e científica.

Teoricamente, portanto, 0 artigo dialoga com 0 pensamento da complexidade, com a EA Crítica e com a Ecologia Política (LIPIETZ, 2002; MORIN, 2007, 2009; LIMA, 2008).

Quando se observam as escolas no Brasil e se a Educação Ambiental é desenvolvida em contextos escolares, percebe-se que $94 \%$ das escolas do ensino fundamental afirmam praticar a EA. Essa ampla ocorrência, contudo, quando submetida a uma análise mais atenta, revela contradições entre o discurso e a prática que aparecem na rigidez curricular, em uma prática interdisciplinar incipiente, em uma pedagogia conteudista e comportamentalista, na baixa incorporação dos problemas locais, dos conflitos sociais e das relações com as comunidades do entorno e na escassa adesão à prática de reciclagem do lixo (TRAJBER; MENDONÇA, 2007; TOZONI-REIS, 2014; VIEGAS; NEIMAN, 2015; TEIXEIRA et al., 2019).

Essa caracterização estimula outras questões, tais como: a Educação Ambiental praticada tem promovido articulação com 0 projeto políticopedagógico e o currículo? A Educação Ambiental é uma prática diária nas escolas? $\mathrm{O}$ processo pedagógico tem tratado a problemática socioambiental como objeto complexo, interdisciplinar e multidimensional? São perguntas que podem ajudar a entender a inserção da EA no espaço formal da educação.

Esta pesquisa teve como objetivo geral analisar a dinâmica do processo pedagógico de escolas de ensino básico no município de Mossoró, Rio Grande do Norte, quanto ao desenvolvimento da Educação Ambiental crítica. Como objetivos específicos, tem-se: compreender a articulação do PPP e do currículo das escolas com os temas ambientais; identificar as características da prática pedagógica realizada e as percepções dos educadores sobre noções constituintes da Educação Ambiental.

\section{Material e métodos}

A pesquisa adota uma abordagem qualitativa com complemento de dados quantitativos. Segundo Minayo (2010), a pesquisa qualitativa procura compreender os significados, os motivos, as representações e percepções que os sujeitos constroem em sua relação com o mundo e com os objetos pesquisados. São aspectos da realidade que fogem à mensuração quantitativa e dão sentido às ações humanas e aos dados coletados na pesquisa.

O trabalho aborda três dimensões do processo pedagógico: o PPP, o 
currículo e a prática pedagógica. Os critérios para as escolhas dessas dimensões da escola e da escolaridade se justificam por sua importância norteadora de toda a dinâmica socioeducativa da escola. O PPP porque é o documento estratégico que estabelece a filosofia, as prioridades e os objetivos da escola, orienta a proposta curricular, as metodologias a serem empregadas, as diretrizes sobre a formação dos professores, além da gestão administrativa. O currículo porque aponta os conteúdos temáticos, a proposta pedagógica, os valores a serem exercitados, as adequações à cultura e aos problemas locais e as estratégias metodológicas para a concretização do PPP. Por fim, as práticas pedagógicas que são o lócus da aprendizagem, da relação professor-aluno e da efetivação concreta dos dois documentos anteriores.

Os aportes teóricos da Educação Ambiental crítica foram retratados segundo os princípios tipificados a partir da literatura e dos debates que os tematizam, conforme o Quadro 1.

Quadro 1: Princípios da Educação Ambiental Crítica.

\begin{tabular}{|l|}
\hline 1. Estabelecer uma visão de mundo complexa e multidimensional \\
\hline 2. Buscar a transformação e emancipação da sociedade \\
\hline 3. Discutir sobre as redes de interações entre sociedade e ambiente \\
\hline 4. Integrar as dimensões individuais e coletivas da sociedade \\
\hline 5. Estimular mudanças de atitudes \\
\hline 6. Permitir a participação social \\
\hline 7. Desenvolver a práxis - ação/reflexão no processo pedagógico \\
\hline 8. Promover a criatividade e inovação \\
\hline 9. Inserir as questões éticas e políticas na relação entre a educação e o ambiente \\
\hline 10. Contextualizar os conteúdos educativos \\
\hline 11. Utilizar no processo de ensino-aprendizagem metodologias interdisciplinares \\
\hline 12. Incentivar a autonomia dos sujeitos
\end{tabular}

Fonte: adaptado de Lima (2008).

A área de abrangência da pesquisa foi o ensino fundamental I, $1^{\circ}$ ao $5^{\circ}$ ano, realizada em três instituições públicas de ensino básico, denominadas Escola A, Escola B e Escola C. O critério de seleção das escolas foi a participação prévia em projetos de Educação Ambiental. A escolha pelo ensino fundamental se deu em função de um único educador ser o responsável por todas as disciplinas, favorecendo a observação dos aspectos que envolvem a disciplinaridade - multi, pluri, inter e transdisciplinaridade. Foi selecionada apenas uma sala de aula de cada ano por escola, utilizando como critério de escolha a disponibilidade do educador para participar da pesquisa. 
Os instrumentos utilizados na pesquisa foram os seguintes: pesquisa bibliográfica, para caracterizar o marco teórico do campo de estudo; pesquisa documental, com o objetivo de levantar os dados que contemplavam as dimensões dos PPPs e dos programas curriculares das escolas; observação sistemática e assistemática das aulas, para caracterizar a prática pedagógica e grupos focais com roteiros semiestruturados reunindo educadores, professores, supervisores e diretor em um único encontro em cada uma das escolas. A pesquisa seguiu os protocolos éticos exigidos pela Resolução $n^{\circ}$ 196/96 do Conselho Nacional de Saúde/Ministério da Saúde, com o registro CAAE № 0006.0126.126-11.

A amostragem das aulas para caracterizar a prática pedagógica envolveu educadores e educandos de 11 salas de aula nas três escolas, sendo, três amostras na Escola A, cinco na Escola B e três na Escola C. Nos grupos focais, centrados na percepção dos educadores, participaram um total de 19 educadores, sendo na Escola A cinco participantes; na Escola B, dez; e na Escola $\mathrm{C}$ quatro.

As escolas pesquisadas estão situadas no município de Mossoró, no oeste do estado do Rio Grande do Norte. Uma das escolas está localizada na zona rural, ofertando educação infantil e ensino fundamental I e II e possuía, durante o período em que a pesquisa foi realizada, cinco salas de aula, cozinha, banheiros, secretaria, direção, sala de professores, biblioteca, sala de informática e área livre. No ano de 2010, a escola foi nomeada pela Gerência Executiva do Meio Ambiente e Gerência Executiva da Educação e do Desporto da Prefeitura Municipal de Mossoró (PMM) como primeiro Núcleo de Educação Ambiental na zona rural do município.

A segunda escola pesquisada está situada no bairro Alto de São Manoel, com educação infantil, ensino fundamental I e II e o programa ProJovem Urbano. A escola dispunha, durante o período em que a pesquisa foi realizada, de sete salas de aula, sala multimídia, secretaria, biblioteca, diretoria, arquivo, banheiros e uma quadra de esportes. Em 2006 a escola recebeu o prêmio Sala Verde, concedido pela Gerência do Meio Ambiente da PMM ao Núcleo de Educação Ambiental que mais desenvolveu atividades voltadas à proteção do meio ambiente naquele ano.

A terceira escola submetida à pesquisa está posicionada na periferia da cidade, no bairro Belo Horizonte, oferecendo à comunidade o ensino fundamental I e II, ensino médio e a educação para jovens e adultos. Sua estrutura física, no período de realização da presente pesquisa, era constituída de nove salas de aula, biblioteca, pátio, cozinha, banheiros, sala de vídeo, sala de professores, secretaria, direção e supervisão, um campo de futebol e uma área livre.

As duas últimas escolas ofertavam atividades no contraturno por meio do programa Mais Educação, apoiado pelos Ministérios da Educação, Esporte, Cultura e Desenvolvimento Social e Combate à Fome do Governo Federal. 
Alguns dados que contextualizam Mossoró: o Índice de Desenvolvimento Humano (IDH) do município em 2010 foi de 0,720; o Índice de Desenvolvimento da Educação Básica (ldeb) nos anos iniciais do ensino fundamental, em 2017, de 5,3, e nos anos finais, de 3,7. A taxa de escolarização de 6 a 14 anos de idade, em 2010, apresentou percentual de $97,7 \%$ (IBGE, 2020). Ainda segundo o IBGE, a cidade destacou-se pelo potencial econômico das atividades de extração de petróleo, fruticultura irrigada, produção de sal, mineração e a carcinocultura. Em 2020, possuía uma população estimada de 300.618 habitantes inseridos em uma região do semiárido Nordestino.

\section{Resultados e discussão}

\section{Projetos Político-Pedagógicos (PPPs)}

O projeto político-pedagógico tem o objetivo de ser o eixo norteador do processo pedagógico em sentido amplo. Isto implica em construir as concepções centrais que a escola adota, especialmente quanto aos fundamentos pedagógicos. Ele representa um caminho futuro através de um sentido definido e de uma ação educativa intencional para percorrer uma trajetória a partir do que se tem para chegar ao que se deseja (GADOTI, 1998).

O PPP da Escola A definiu as diretrizes do processo pedagógico e estabeleceu sua função social de sistematizadora de conhecimentos. Neste sentido, objetivou organizar, reproduzir e construir conhecimentos com o envolvimento dos pais e da comunidade externa para estabelecer uma gestão democrática e edificar uma sociedade justa, humana e igualitária. Perseguiu, assim, a formação de cidadãos críticos, íntegros, conscientes e comprometidos com a ciência, respeitando as diferenças individuais, a diversidade cultural e os valores indispensáveis à vida. Sua metodologia foi baseada no diálogo, utilizando estratégias participativas e coletivas entre os sujeitos, para que o educando aprenda a aprender, utilizando temas transversais que possam contextualizar os conteúdos.

A Escola B tinha um PPP que se apresentava como referência no processo pedagógico de todas as suas atividades. $\mathrm{O}$ documento situava a escola como um dos espaços socioeducativos e ressaltava sua importância pela proximidade com o rio Apodi/Mossoró, posicionando a escola como um local de debate, para tratar questões socioambientais como o saneamento básico, por exemplo. A escola assumia a responsabilidade de organizar, sistematizar, transmitir conhecimentos formais, valores e preceitos éticos a fim de constituir cidadãos críticos, criativos, reflexivos e participativos capazes de tornar a sociedade justa, fraterna e solidária. Desta forma a gestão democrática, a inovação, o respeito ao indivíduo e a pluralidade cultural colocavam-se como estratégias de sua administração. A base pedagógica da escola B estava pautada pela teoria socioconstrutivista.

O PPP da Escola $C$ tinha como proposta estabelecer o desenvolvimento físico, psicológico e cultural dos educandos para torná-los conscientes de seus 
direitos e deveres e aptos a intervir nos problemas da escola. Para tanto, tinha como perspectiva pedagógica formar educandos criativos, autônomos e participativos para atuar e transformar a sociedade, construindo princípios de igualdade, liberdade, justiça, democracia, valorização dos sujeitos e solidariedade.

Nessas sínteses fica claro que o PPP pode ser visto como uma carta de intenções e, neste sentido, deve-se reconhecer que as escolas nem sempre realizam o que desejam, como afirma a educadora da Escola C:

A gente sabe que tá longe da realidade (se refere ao PPP), porque eu tenho certeza que aqui, os professores têm pouco conhecimento dele. Até porque quando se termina de digitar um PPP já tem que começar tudo de novo, atualizar, já chegaram novos programas. Aí não temos tempo de viver o PPP porque já tem que começar tudo de novo. [...] O próprio governo não deixa que as coisas aconteçam, a gente se prepara para a aula, como foi o caso do pró-letramento, foi dois anos de preparação, não passou nenhum ano e já mudaram de novo (Grupo focal Escola C).

$\mathrm{Na}$ Tabela 1, é reportado quais princípios da Educação Ambiental crítica foram contemplados nos PPPs analisados.

Tabela 1: Princípios da Educação Ambiental Crítica identificados nos projetos políticopedagógicos (PPP) das Escolas avaliadas (Mossoró, Rio Grande do Norte)

\begin{tabular}{|c|c|c|c|}
\hline \multirow{2}{*}{ Princípios da Educação Ambiental Crítica } & \multicolumn{3}{|c|}{ PPP da Escola } \\
\hline & A & B & C \\
\hline 1. Estabelecer uma visão de mundo complexa e multidimensional & & & $x$ \\
\hline 2. Buscar a transformação e emancipação da sociedade & $x$ & $X$ & $\mathrm{X}$ \\
\hline 3. Discutir sobre as redes de interações entre sociedade e ambiente & & & \\
\hline 4. Integrar as dimensões individuais e coletivas da sociedade & $\mathrm{X}$ & $\mathrm{X}$ & $\mathrm{X}$ \\
\hline 5. Estimular mudanças de atitudes & & & \\
\hline 6. Permitir a participação social & $X$ & $X$ & $\mathrm{X}$ \\
\hline 7. Desenvolver a práxis - ação/reflexão no processo pedagógico & $\mathrm{X}$ & $\mathrm{X}$ & $\mathrm{X}$ \\
\hline 8. Promover a criatividade e inovação & & $\mathrm{X}$ & $\mathrm{x}$ \\
\hline $\begin{array}{l}\text { 9. Inserir as questões éticas e políticas na relação entre a educação e o } \\
\text { ambiente }\end{array}$ & $X$ & $X$ & $\mathrm{X}$ \\
\hline 10. Contextualizar os conteúdos educativos & $\mathrm{X}$ & $\mathrm{X}$ & $\mathrm{X}$ \\
\hline $\begin{array}{l}\text { 11. Utilizar no processo de ensino-aprendizagem metodologias } \\
\text { interdisciplinares }\end{array}$ & $x$ & $X$ & $\mathrm{x}$ \\
\hline 12. Incentivar a autonomia dos sujeitos & $\mathrm{X}$ & $\mathrm{X}$ & $\mathrm{X}$ \\
\hline
\end{tabular}

Fonte: pesquisa de campo. 
Constatou-se a ausência dos princípios de complexidade e multidimensionalidade nas Escolas A e B, que servem como indicadores para avaliar o tipo de abordagem da questão ambiental. Certamente, se 0 entendimento da realidade não é compatível com sua complexidade, as soluções propostas não serão suficientes para sua superação. Isso não quer dizer que a presença do princípio na Escola $C$ garanta essa premissa. Como dito no grupo focal (Escola C) citado acima, os professores têm pouco conhecimento do PPP e mudanças constantes contribuem para fragilizar seu papel.

Para Morin (2009), compreender o mundo como uma rede de interrelações complexas decorre de uma posição de abertura à reflexão sobre o mundo. Para tanto, ele aponta para a reforma que renova o pensamento e contrapõe o que chama de uma cabeça bem-feita a uma cabeça bem cheia. Para formar uma cabeça bem-feita, o sujeito precisa dispor de aptidão para analisar e tratar os problemas e incorporar princípios que permitam conectar os diversos saberes e lhes dar sentido. Já a cabeça bem cheia acumula informações, mas não permite ao indivíduo refletir criticamente sobre sua realidade e atribuir a esta significados, resultando em um movimento meramente mecânico.

Outro ponto a ser destacado é a lacuna de uma articulação entre sociedade e ambiente no PPP das três escolas. A dissociação entre o ambiente e a sociedade despolitiza o debate e desconsidera os conflitos entre os interesses públicos e privados no acesso e uso dos recursos naturais. Com isso, a leitura dos problemas ambientais fica limitada à percepção das consequências finais do processo sem a identificação apropriada de suas causas.

A Ecologia política chama atenção sobre esse aspecto da relação entre sociedade e ambiente quando questiona o modo como um determinado padrão de organização social produz, simultaneamente, degradação social e ambiental. Nesses termos, o modelo de desenvolvimento capitalista que é a causa primária de uma série de problemas socioambientais, dentre eles a desigualdade socioambiental, não é problematizada. Isso dificulta qualquer tentativa de abordar e promover justiça socioambiental porque as soluções possíveis são construídas a partir de uma análise fundada apenas nas consequências dos problemas. Por essa razão, Acselrad (1992) faz a advertência óbvia, mas necessária, de que os problemas ambientais não são problemas da natureza, mas problemas sociais que se manifestam na natureza.

Não encontrar no texto dos PPPs analisados o estímulo a mudanças de atitude pode sugerir que o foco das escolas se concentra na mudança de comportamento. Geralmente, as atividades em Educação Ambiental estão voltadas para a mudança de comportamentos individuais gerada a partir da difusão de conhecimentos ecológicos, como aponta Loureiro (2008). É o que ocorre quando se estuda a problemática do lixo sem debater o consumo, por 
exemplo. Essa ênfase no comportamento e na responsabilização dos indivíduos tem efeitos danosos sobre a formação dos educandos, porque reduz a questão ambiental ao âmbito da esfera privada e incorre em um julgamento injusto ao homogeneizar as responsabilidades de agentes muito diferentes entre si, como são os governos, as empresas e os indivíduos. Além disso, a adoção dessa perspectiva obscurece a compreensão política dos fenômenos, dificultando o despertar do espírito de cidadania e de possíveis ações ecopolíticas (LAYRARGUES; LIMA, 2014; SANTOS et al., 2017; LAYRARGUES, 2020).

Observa-se, portanto, que os princípios da EA crítica estão sendo incorporados pelos PPPs, entretanto esta dimensão do processo pedagógico situa-se no campo abstrato, como forma de orientar o projeto e definir seu sentido. A sua tradução em ações concretas depende de outras dimensões do processo educativo como o currículo e a prática pedagógica, como veremos adiante.

\section{Programas Curriculares}

O currículo cumpre funções estratégicas no processo pedagógico ao definir os conteúdos disciplinares e apresentar planos metodológicos, enquanto o PPP tem a intenção de nortear esse processo. Há, portanto, uma relação entre fins (PPP) e meios (currículo). Nesse processo, conjuga-se uma diversidade de concepções curriculares, derivadas de diferentes visões de educação, assim como de influências teóricas que assumem status hegemônico em um dado período histórico (MOREIRA; CANDAU, 2008).

A Educação Ambiental e o tema meio ambiente aparecem nos programas curriculares das Escolas A, B e C por meio da pedagogia de projetos. Essa estratégia metodológica é identificada por Rodrigues et al. (2019) como a mais utilizada em atividades de EA. Os projetos utilizam temas geradores associados às questões ambientais comunitárias e envolvem diversos educadores e disciplinas nas atividades desenvolvidas.

Nos documentos nacionais as noções de transversalidade e de interdisciplinaridade são adotadas para a inserção dos temas transversais. A interdisciplinaridade atua no campo epistemológico, contrapondo-se à visão disciplinar, já a transversalidade diz respeito à dimensão didática de como internalizar a experiência da realidade a partir da utilização prática dos conhecimentos da vivência cotidiana (BRANCO; ROYER; BRANCO, 2018).

O conceito de interdisciplinaridade não é um conceito fácil de ser apreendido. O conhecimento científico se estruturou historicamente de modo cartesiano, analítico e disciplinar, e as escolas 0 assimilam desse modo. Portanto, superar a disciplinaridade exige a reforma do pensamento (MORIN, 2009). Por outro lado, a transversalidade também nos traz desafios. O tema meio ambiente pode estar em todas as disciplinas, mas também em lugar nenhum, como alerta Carvalho (2005). Essas dificuldades teóricas e práticas 
da interdisciplinaridade e da transversalidade são verificadas na escola, na estrutura do currículo, e na definição dos conceitos apresentados pelos educadores que também obedecem a uma base disciplinar. Ainda que não seja muito frequente, em alguns casos, os professores e a escola se arriscam a reunir disciplinas diferentes.

Com relação à identificação dos princípios da Educação Ambiental crítica nos currículos das Escolas, os princípios de contextualização dos conteúdos, de utilização da metodologia interdisciplinar e o incentivo à autonomia dos sujeitos foram identificados nas propostas de todas as escolas pesquisadas (Tabela 2 ).

Tabela 2: Princípios da Educação Ambiental Crítica identificados nos programas curriculares das Escolas avaliadas (Mossoró, Rio Grande do Norte).

Princípios da Educação Ambiental Crítica

\section{Currículo}

A B C

1. Estabelecer uma visão de mundo complexa e multidimensional

2. Buscar a transformação e emancipação da sociedade

3. Discutir sobre as redes de interações entre sociedade e ambiente

4. Integrar as dimensões individuais e coletivas da sociedade

5. Estimular mudanças de atitudes

6. Permitir a participação social $X$

7. Desenvolver a práxis - ação/reflexão no processo pedagógico $\quad X$

8. Promover a criatividade e inovação $\mathrm{X}$

9. Inserir as questões éticas e políticas na relação entre a educação e o ambiente

\begin{tabular}{llll}
\hline 10. Contextualizar os conteúdos educativos & $X$ & $X$ & $X$ \\
\hline $\begin{array}{l}\text { 11. Utilizar no processo de ensino-aprendizagem metodologias } \\
\text { interdisciplinares }\end{array}$ & $X$ & $X$ & $X$ \\
\hline 12. Incentivar a autonomia dos sujeitos & $X$ & $X$ & $X$ \\
\hline
\end{tabular}

Fonte: pesquisa de campo.

A quantidade de princípios identificados nos programas curriculares é menor do que a identificada nos PPPs. $O$ que nos sugere a integração das dimensões pedagógicas até aqui retratadas - ou, pelo menos, suscita uma reflexão a respeito disso. Lima (2007) aponta que não há currículo ingênuo; sua composição, em geral, supõe uma escolha. Daí, pode-se considerar que a interdisciplinaridade, a autonomia e a contextualização dos conteúdos, por exemplo, podem aparecer como forma de atualizar discursivamente o processo pedagógico e de legitimar o programa, sem, contudo, transformar o modelo curricular tradicional. Por outro lado, também é possível compreendê-los como ensaios estratégicos para possíveis transformações pedagógicas e sociais.

A Escola $B$ revelou um maior número de princípios educativos críticos, o que pode demonstrar um esforço para tornar efetiva uma prática pedagógica transformadora. Um sinal disso aparece no compromisso firmado pela escola de oferecer merenda escolar saudável por meio da compra direta de frutas, 
verduras e cereais a agricultores familiares que não utilizam agrotóxicos na sua produção. A prática da alimentação saudável também é estimulada por meio do cultivo de hortaliças na escola. Segundo uma das educadoras da escola, projetos com esse caráter não eram ampliados pela falta de estrutura e apoio técnico.

A participação social dos pais e responsáveis pelos alunos e da comunidade revelou-se uma prática democratizante incentivada pela gestão da Escola B. Essa mesma participação também foi observada nos eventos e reuniões da escola, embora ainda seja um processo inicial, que carece de amadurecimento. A escola criou um espaço virtual de divulgação de suas atividades por meio de um blog e sempre busca parcerias com universidades e organizações não governamentais para desenvolvimento de projetos. As parcerias externas são esforços valiosos que fazem avançar a democratização da gestão e que trazem benefícios à formação dos docentes e à aproximação entre escola e sociedade (SANTOS et al., 2017).

A Escola $B$ apresentou um processo pedagógico com maior integração entre o PPP e o currículo. A gestão democrática e a criatividade foram recursos utilizados para enfrentar desafios na construção do projeto coletivo da escola, e com o envolvimento de todos. As Escolas A e C, ao contrário, demonstraram ainda manter relações hierárquicas rígidas e dotadas de menor criatividade.

\section{As Práticas Pedagógicas}

A análise da prática pedagógica avaliou a ação particular de cada educador enquanto membro do projeto educativo da escola. Nos grupos focais, relatou-se que a EA é uma prática diária, não limitada a datas comemorativas ou ações pontuais restritas a determinadas disciplinas. Quando a sala é o ponto de partida $e$ as atividades não se restringem a ações comportamentalistas, a prática educativa tem o potencial de mudar a percepção e a ação dos educandos sobre o mundo e no mundo. Isso pode ser observado nos grupos focais a seguir:

Na minha sala de aula (a Educação Ambiental) praticamente é diária. A questão de cooperação, de atitudes certas e erradas, de quebrar e de não quebrar (materiais e equipamentos da escola), de manter o ambiente, o espaço que você está estudando arrumado, de saber trabalhar com o outro, de tratar a escola como se fosse uma segunda casa. [...] (Grupo focal Escola C).

A Educação Ambiental é muito ampla, então é trabalhada diariamente. Além dos conteúdos ela também é trabalhada nas atitudes dos alunos. Quando a gente explica que o aluno não pode colocar o lixo no chão, manter a sala arrumada, limpa, então essas já são ações educativas. Além dos projetos que favorecem mais ainda a ampliação dos conteúdos (Grupo focal Escola A). 
A concepção de meio ambiente, na perspectiva da EA crítica, integra as dimensões social e natural no construto "socioambiental" porque percebe que os problemas estudados são decorrentes do modo como as pessoas, os grupos e as classes se relacionam socialmente e com o meio ambiente. Ou seja, é uma abordagem que vai além de uma consideração meramente ecológica e conservacionista da natureza. Daí o educando começa a perceber a inter-relação entre a ação humana e o ambiente e a complexidade das causas e efeitos que compõem essa interação. Alguns relatos de professores indicam essa situação:

Com a ampliação do nosso conhecimento sabemos que o meio ambiente não é só isso (plantas e animais), é uma coisa muito mais ampla (se refere à dimensão social) [...] (Grupo focal Escola A).

Outro dia um menino olhou para mim e disse: tia eu 'tava assim olhando. Todo dia tem um Senhor que limpa a casa do cachorro e joga dentro do rio. Eu não aguentei mais e disse assim: ei, Senhor, não jogue no rio porque polui a água. Aí ele disse: nada, quando chover a água vai para outro canto. Ai eu respondi: lá vai poluir também (Grupo focal Escola B).

No grupo focal da Escola A, observou-se a percepção ambiental do educador e sua busca por ampliar a consciência e o conhecimento dos problemas. A capacitação dos professores contribui com a ampliação dessa percepção e o reconhecimento do papel da EA (OLIVEIRA; AMARAL, 2020). Para Blanco et al. (2020), não quer dizer que o professor que recebe capacitação incorporará a EA no currículo escolar, entretanto o educador capacitado, uma vez que decida por inseri-la em seu currículo, poderá ter mais êxito na abordagem e mediação desse saber.

No cotidiano da sala de aula contextualizar o conteúdo, partir da experiência concreta do educando, problematizar a paisagem da rua, do bairro e da cidade e as condições materiais que estão diretamente relacionadas à qualidade de vida abrem caminhos de debates e permitem a inserção de dimensões éticas e políticas às aulas (CAGLIONI et al., 2021).

Chen e Liu (2020), em sua pesquisa de revisão do conceito de competência de ação como uma abordagem instrucional para um futuro sustentável, defendem a participação dos alunos, o exercício da interação entre causas e efeitos e da capacidade de resolver problemas, como podemos observar no grupo focal da Escola B.

A prática que incorpora esses elementos pode estimular mudanças de atitudes, vai além do conteudismo e pode motivar mudanças no ambiente, seja na escola ou fora dela, como observamos nos depoimentos que seguem: 
Quando você trabalha o bairro: como é o bairro? É poluído? Jogam lixo na rua? Tem rede de esgoto? A arborização como é? Se existe? Destroem? Estão tirando e colocando no canto certo? [...] (Grupo focal Escola B).

O educando vai desenvolver uma atitude, não só aprendeu o conteúdo, ele associou à prática. Está se plantando consciência, uma aqui outra acolá. É um processo [...], não se dá de uma vez só (Grupo focal Escola B).

Será que colocando um cesto de lixo em cima da mesa vai fazer com que eu mostre ao meu aluno que é preciso conservar o ambiente limpo? Não, eu mostro ao meu aluno que ele tem que produzir menos lixo, que aquele lixo pode estar sendo colocado em um local apropriado, aí sim eu vou trabalhar uma Educação Ambiental com meu aluno. Eu acredito que esse fazer é que norteia, que faz fortalecer o currículo, o PPP, é o que faz fortalecer todas as dimensões da ação pedagógica ao trabalhar as questões ambientais e outras mais (Grupo focal Escola B).

Nas falas dos educadores foi possível identificar e caracterizar a Educação Ambiental. Nas Tabelas 3 e 4, são descritas as práticas pedagógicas desenvolvidas no cotidiano escolar por meio da observação em sala de aula.

Tabela 3: Sistematização dos dados coletados da observação sistemática e assistemática na prática pedagógica das Escolas A, B e C (parte 1)

\begin{tabular}{|c|c|c|c|c|}
\hline Escola & Tema/Conteúdo & Metodologia & $\begin{array}{l}\text { Estimula a criatividade e } \\
\text { reflexão }\end{array}$ & Provoca interação \\
\hline$A(1)$ & $\begin{array}{l}\text { Meio ambiente: ar, } \\
\text { água, solo e seres } \\
\text { vivos }\end{array}$ & Multi & $\begin{array}{l}\text { É utilizada a leitura de } \\
\text { imagens }\end{array}$ & $\begin{array}{l}\text { Sim, por meio de } \\
\text { questionamentos }\end{array}$ \\
\hline A (2) & $\begin{array}{c}\text { Mudanças nas } \\
\text { cidades brasileiras } \\
\text { no século XX } \\
\end{array}$ & Multi & $\begin{array}{l}\text { É utilizada a leitura individual } \\
\text { e coletiva }\end{array}$ & $\begin{array}{l}\text { Sim, por meio do } \\
\text { esclarecimento das } \\
\text { dúvidas }\end{array}$ \\
\hline A (3) & $\begin{array}{c}\text { A água no } \\
\text { contexto do } \\
\text { planeta terra }\end{array}$ & Pluri & $\begin{array}{l}\text { É realizada uma caminhada } \\
\text { pela comunidade }\end{array}$ & $\begin{array}{l}\text { Sim, por meio do } \\
\text { diálogo }\end{array}$ \\
\hline$B(1)$ & $\begin{array}{l}\text { Clima e tempo: } \\
\text { cuidando do solo }\end{array}$ & Disciplinar & É utilizado questionário & $\begin{array}{c}\text { Sim, por meio da } \\
\text { definição de conceitos }\end{array}$ \\
\hline B (2) & $\begin{array}{l}\text { Consumo de } \\
\text { energia } x \text { meio } \\
\text { ambiente }\end{array}$ & Disciplinar & $\begin{array}{l}\text { É utilizada leitura de } \\
\text { imagens }\end{array}$ & $\begin{array}{l}\text { Sim, por meio de } \\
\text { questionamentos }\end{array}$ \\
\hline B (3) & $\begin{array}{l}\text { Herdeiros do } \\
\text { futuro (ética) }\end{array}$ & Disciplinar & $\begin{array}{c}\text { São utilizadas leitura } \\
\text { coletiva, ilustrações e } \\
\text { questionamentos }\end{array}$ & $\begin{array}{c}\text { Sim, por meio da } \\
\text { leitura e interpretação } \\
\text { de texto }\end{array}$ \\
\hline B (4) & Água: rio e mar & Inter & $\begin{array}{l}\text { São utilizados a } \\
\text { interpretação de texto, } \\
\text { reescrita de texto e } \\
\text { questionário }\end{array}$ & $\begin{array}{l}\text { Sim, por meio da } \\
\text { leitura individual e } \\
\text { coletiva }\end{array}$ \\
\hline
\end{tabular}

Continua...

Revbea, São Paulo, V. 16, № 3: 59-78, 2021.

revista brasileira 
...continuação.

\begin{tabular}{ccccc}
\hline Escola & Tema/Conteúdo & Metodologia & $\begin{array}{c}\text { Estimula a criatividade e } \\
\text { reflexão }\end{array}$ & Provoca interação \\
\hline B (5) & $\begin{array}{c}\text { Festas juninas e o } \\
\text { meio ambiente }\end{array}$ & Inter & $\begin{array}{c}\text { É utilizada a leitura do texto } \\
\text { com o debate de conceitos } \\
\text { por meio de palavras-chave }\end{array}$ & $\begin{array}{c}\text { Sim, por meio de } \\
\text { questionamentos }\end{array}$ \\
\hline C (1) & $\begin{array}{c}\text { Dia do meio } \\
\text { ambiente }\end{array}$ & Disciplinar & $\begin{array}{c}\text { É utilizada a leitura de } \\
\text { imagens }\end{array}$ & $\begin{array}{c}\text { Sim, por meio da } \\
\text { definição de problemas } \\
\text { ambientais }\end{array}$ \\
\hline C (2) & Gato pedrês & Multi & $\begin{array}{c}\text { São utilizadas a } \\
\text { interpretação de texto, sons } \\
\text { e imagens gráficas }\end{array}$ & $\begin{array}{c}\text { Sim, por meio da } \\
\text { leitura coletiva e de } \\
\text { questionamentos }\end{array}$ \\
\hline C (3) & $\begin{array}{c}\text { O mercadinho de } \\
\text { frutas }\end{array}$ & Inter & $\begin{array}{c}\text { Foi montada uma banca de } \\
\text { frutas, trazidas pelos alunos } \\
\text { e depois consumidas }\end{array}$ & $\begin{array}{c}\text { Sim, por meio da } \\
\text { leitura coletiva e de } \\
\text { questionamentos }\end{array}$ \\
\hline
\end{tabular}

Fonte: pesquisa de campo.

Tabela 4: Sistematização dos dados coletados da observação sistemática e assistemática na prática pedagógica das Escolas A, B e C (parte 2).

\begin{tabular}{|c|c|c|c|c|}
\hline Escola & Tema/Conteúdo & $\begin{array}{c}\text { Diálogo entre a teoria } \\
\text { e a prática }\end{array}$ & $\begin{array}{c}\text { Material didático } \\
\text { utilizado }\end{array}$ & Participação \\
\hline$A(1)$ & $\begin{array}{l}\text { Meio ambiente: ar, } \\
\text { água, solo e seres } \\
\text { vivos }\end{array}$ & $\begin{array}{l}\text { O diálogo aparece de } \\
\text { forma tímida }\end{array}$ & $\begin{array}{l}\text { Mapa, quadro e livro } \\
\text { didático }\end{array}$ & Alguns \\
\hline A (2) & $\begin{array}{c}\text { Mudanças nas } \\
\text { cidades brasileiras } \\
\text { no século XX }\end{array}$ & $\begin{array}{c}\text { O dialogo ocorre a partir } \\
\text { da percepção dos } \\
\text { alunos }\end{array}$ & $\begin{array}{c}\text { Data show - slide, fontes } \\
\text { alternativas de pesquisa e } \\
\text { o quadro }\end{array}$ & Maioria \\
\hline A (3) & $\begin{array}{l}\text { A água no contexto } \\
\text { do planeta Terra }\end{array}$ & $\begin{array}{c}\text { O diálogo se dá a partir } \\
\text { da visita ao rio }\end{array}$ & $\begin{array}{c}\text { Texto, quadro, livro } \\
\text { didático e fontes } \\
\text { alternativas de pesquisa }\end{array}$ & Maioria \\
\hline$B(1)$ & $\begin{array}{l}\text { Clima e tempo: } \\
\text { cuidando do solo }\end{array}$ & Não & Texto e filme & Maioria \\
\hline B (2) & $\begin{array}{l}\text { Consumo de } \\
\text { energia } x \text { meio } \\
\text { ambiente }\end{array}$ & Não & $\begin{array}{l}\text { Quadro, painel com jornal } \\
\text { e imagens, música, } \\
\text { cruzada e livro didático }\end{array}$ & Maioria \\
\hline B (3) & $\begin{array}{l}\text { Herdeiros do futuro } \\
\text { (ética) }\end{array}$ & Não & Imagens e contos & Maioria \\
\hline $\mathrm{B}(4)$ & Água: rio e mar & Não & Livro didático & Maioria \\
\hline B (5) & $\begin{array}{l}\text { Festas juninas e o } \\
\text { meio ambiente }\end{array}$ & $\begin{array}{l}\text { O diálogo é suscitado a } \\
\text { partir da realidade dos } \\
\text { alunos }\end{array}$ & $\begin{array}{c}\text { Data show-slide e } \\
\text { música }\end{array}$ & Maioria \\
\hline C (1) & $\begin{array}{l}\text { Dia do meio } \\
\text { ambiente }\end{array}$ & $\begin{array}{l}\text { O diálogo aparece de } \\
\text { forma tímida }\end{array}$ & Data show - slide & Alguns \\
\hline C (2) & Gato pedrês & $\begin{array}{l}\text { O diálogo aparece de } \\
\text { forma tímida }\end{array}$ & $\begin{array}{c}\text { Livro paradidático e } \\
\text { material do programa Alfa } \\
\text { e Beto }\end{array}$ & Maioria \\
\hline C (3) & $\begin{array}{l}\text { O mercadinho de } \\
\text { frutas }\end{array}$ & $\begin{array}{l}\text { O diálogo é suscitado a } \\
\text { partir da utilização das } \\
\text { frutas }\end{array}$ & Frutas e o quadro & Alguns \\
\hline
\end{tabular}

Fonte: pesquisa de campo. 
A metodologia adotada pelos educadores atravessava os conceitos disciplinar, pluridisciplinar, multidisciplinar e interdisciplinar. A disciplinaridade é um conjunto específico de conhecimentos que possui conceitos e características próprias e tem fronteiras bem definidas. A multidisciplinaridade reúne várias disciplinas, mas mantém os limites de cada uma delas. A pluridisciplinaridade busca instituir relações complementares entre as disciplinas, trocando informações e conhecimentos. $\mathrm{Na}$ interdisciplinaridade, a ideia é construir novos referenciais teóricos e metodológicos a partir do diálogo entre as disciplinas e entre os saberes sem pretensão de cientificidade (SOMMERMAN, 2006; CARVALHO, 2008).

Os temas socioambientais vão além do terreno disciplinar. Mesmo entendendo que a multi e a pluridisciplinaridade ainda são estratégias metodológicas limitadas, elas já representam algum avanço. A incorporação do princípio da interdisciplinaridade vem para contribuir e ampliar a compreensão do mundo de forma a visualizá-lo como complexo e multidimensional (MARVILA; GUISSO, 2019). Para Melo, Carvalho e Sampaio (2020, p. 52), a "EA tem como foco principal uma ação interdisciplinar que relaciona o homem, a natureza e o universo".

A pesquisa também tratou dos métodos de abordagem dos temas e problemas ambientais. Neste sentido, identificou-se, nas escolas pesquisadas, o uso da leitura de imagens, as leituras individual e coletiva, caminhadas na comunidade, o uso de questionários, a utilização da escrita, da interpretação de textos, de sons e imagens, os debates e a montagem de uma banca de frutas frescas. Esse último recurso consistiu em criar um ambiente que reproduzisse um mercado público para permitir a convergência de conteúdos disciplinares.

Quanto à interação professor-aluno, identificaram-se as seguintes estratégias: questionamentos, dúvidas, diálogo, definição de conceitos, leituras individual e coletiva e interpretação de texto. $\mathrm{Na}$ associação entre teoria e prática, a Escola $A(3)$ utilizou uma visita ao rio que fica próximo à escola. Quando o componente que relaciona teoria e prática não está presente no processo de ensino-aprendizagem, a produção do conhecimento pode ficar distante da realidade do educando.

Os recursos didáticos utilizados durante as aulas foram: o mapa, o quadro branco, os livros didáticos e paradidáticos, o Data Show, textos de fontes alternativas de pesquisa, filmes, música, palavras-cruzadas, contos literários, banca de frutas e os painéis com jornais e imagens. A Educação Ambiental crítica propõe criatividade e inovação, em que mudanças nos modelos tradicionais podem ser o primeiro passo para novos ambientes de aprendizagem.

Nas Escolas $\mathrm{C}(3)$ e $\mathrm{B}(2)$, consoante as Tabelas 3 e 4, certos princípios da EA crítica foram identificados, como a interdisciplinaridade, a criatividade e a interação entre a teoria e a prática. Entretanto, a prática pedagógica se mostrou pouco dinâmica resultando em baixa participação dos alunos. 
Qualquer processo de classificação das práticas pedagógicas seria apenas um meio de refletir sobre elas, já que esses recursos classificatórios possuem alguns limites. As práticas das escolas que parecem incorporar os princípios da Educação Ambiental crítica são a $A(3), A(4)$ e $B(5)$, conforme as Tabelas 3 e 4 . Isso porque problematizam temas que fazem parte do cotidiano dos educandos, como o rio Apodi/Mossoró (A3 e A4) e as festas juninas (B5). Elas discutem os temas abordados a partir de várias dimensões: cultural, política, técnica, histórica e ética.

Os educandos participaram das atividades mencionadas anteriormente quando questões do seu cotidiano foram debatidas e relataram os comportamentos e atitudes que tiveram em situações vividas. Na observação das práticas in loco perceberam-se ações pontuais como apanhar o papel descartado no chão e a limpeza da sala, por exemplo.

As práticas pedagógicas das demais situações observadas nas três escolas podem ser classificadas como afinadas com a Educação Ambiental conservacionista. $O$ acompanhamento das atividades em campo permitiu observar, nesses casos específicos, a atribuição de uma responsabilização genérica em relação à degradação ambiental, ao fazer uso de expressões como: "o homem", ou "a espécie humana", polui e destrói a natureza. Esse uso de um sujeito abstrato e indeterminado, ao generalizar a responsabilidade de causação dos problemas ambientais a todos os humanos indistintamente, não apenas incorre em uma injustiça como tende a despolitizar o debate possível sobre o tema. As próprias Conferências da ONU que tratam das mudanças climáticas criaram, neste sentido, o princípio universal das responsabilidades comuns, porém diferenciadas (GUIMARÃES; FONTOURA, 2012).

\section{Conclusões}

Observa-se que o PPP é o documento que norteia com fundamentos e orientações as ações da escola, no entanto, possui contorno idealizado, como uma carta de intenções que nem sempre realiza o que deseja. Houve uma tendência à simplificação da problemática socioambiental ao reduzi-la a uma dimensão biologicista e/ou tecnicista e ao despolitizá-la, tornando o debate restrito às suas consequências. Ou seja, o padrão hegemônico de organização capitalista, responsável por produzir a deterioração da qualidade de vida e comprometer os sistemas ecológicos, não entra na pauta de discussão, e quando entra, limita-se a atribuir os problemas ao conjunto de ações individuais, que, somadas, produzem os prejuízos ambientais.

Quanto ao currículo, as escolas tratavam o tema meio ambiente e a EA na perspectiva da pedagogia de projetos, incorporando-os como temas geradores relacionados ao contexto local e que buscavam associar diversas disciplinas. É nítido o esforço em contextualizar os conteúdos, em utilizar metodologias interdisciplinares e incentivar a autonomia dos educandos. No entanto, no que diz respeito à interdisciplinaridade, há dificuldades teóricas e práticas. 
O educador é formado em uma estrutura disciplinar e se depara com um desafio epistemológico, com os parcos recursos que dispõe, diante da interdisciplinaridade. A Escola $B$ se sobressai às demais, ao promover uma prática transformadora e um projeto coletivo utilizando participação social e criatividade para enfrentar os obstáculos inerentes à construção democrática.

A percepção dos educadores sobre noções constituintes da $E A$, nas três escolas analisadas, revelou que a Educação Ambiental é uma prática diária, que a temática ambiental é abordada nas dimensões social e natural e instigam mudanças de comportamentos e atitudes. Além disso, os temas abordados são contextualizados a partir da vivência dos alunos. Desse contraste entre discursos e práticas, destacam-se currículos rígidos e técnicos que não politizam a EA; um conceito de meio ambiente ainda restrito à concepção naturalista e conservacionista; e uma responsabilização genérica da degradação ambiental. Há, contudo, um esforço genuíno dos educadores em desenvolver uma prática pedagógica crítica, que incorpore os problemas e conflitos locais e faça uso de metodologias para além do terreno disciplinar.

$\mathrm{O}$ que possivelmente se revela comum às três dimensões analisadas na pesquisa é a baixa integração entre as dimensões do PPP, do currículo e das práticas pedagógicas. Ou seja, limites que ainda dificultam a transformação da teoria em didática viva. $O$ desafio passa por problematizar a realidade, de articular o social e o natural, de refletir sobre as múltiplas dimensões da questão ambiental, de tratar dos problemas locais, de investigar as causas e não apenas os efeitos dos problemas e de superar o comportamentalismo e a responsabilização dos indivíduos.

Se por um lado, foram identificados limites que criam obstáculos ao projeto emancipatório, por outro, a formação inicial e continuada dos educadores em Educação Ambiental crítica, a oferta de materiais didáticos adequados, as condições de trabalho e da infraestrutura da escola e o fortalecimento das políticas públicas podem contribuir para superá-los. Diante da gravidade das crises climática, ambiental, sanitária e social esses esforços precisam ser multiplicados.

A educação não é a única força transformadora da sociedade. Não cabe exclusivamente à escola assumir esse papel, seria injusto alimentar essa expectativa, mas sem ela, se reduz, sobremodo, o potencial de transformação social. Portanto, não é o educador sozinho que vai operar um projeto emancipatório, no entanto, sem a sua contribuição a mudança dificilmente ocorrerá.

\section{Referências}

ACSELRAD, H. Cidadania e meio ambiente. In: ACSELRAD, H. (org.). Meio Ambiente e Democracia. Rio de Janeiro: IBASE, 1992.

BRANCO, E. P.; ROYER, M. R.; BRANCO, A. B. de G. A abordagem da Educação Ambiental nos PCNs, nas DCNs e na BNCC. Nuances: estudos sobre Educação, Presidente Prudente-SP, v.29, n.1, p.185-203, 2018. 
BLANCO, M. B.; RUDMAN, A. N.; GREENE, L. K.; RAZAFINDRAINIBE, F.; ANDRIANANDRASANA, L.; WELCH, C. (2020) Back to basics: Gaps in baseline data call for revisiting an environmental education program in the SAVA region, Madagascar. PLoS ONE, v.15, p.e0231822, 2020.

BRASIL. Lei № 9.795, de 27 de abril de 1999. Disponível em: http://www.planalto.gov.br/ccivil 03/leis/19795.htm. Acesso em: 20 ago. 2020.

BURSZTYN, M.; BURSZTYN, M. A. Fundamentos de política e de gestão ambiental: os caminhos do desenvolvimento sustentável. Rio de Janeiro: Garamond, 2012.

CAGLIONI, E.; RAMOS, M. R.; OLIVEIRA, D. P. de; MELO, E. J. de; CAMPIGOTTO, S. M. Educação Ambiental nas unidades de ensino básico de Luiz Alves (SC): perfil e percepção docente. Revista Brasileira de Educação Ambiental (RevBEA), v. 16, n. 1, p. 181-201, 4 fev. 2021.

CARVALHO, I. C. M. A invenção do sujeito ecológico: identidades e subjetividade na formação dos educadores ambientais. In: Sato, M.; Carvalho, I. C. M. (org.). Educação Ambiental: pesquisa e desafios. Porto Alegre, Artmed, 2005.

CARVALHO, I. C. M. Educação Ambiental: a formação do sujeito ecológico. 3. ed. São Paulo: Cortez, 2008.

CHEN, S.; LIU, S. Developing Students' Action Competence for a Sustainable Future: A Review of Educational Research. Sustainability, v.12, p.1374, 2020.

CRUTZEN, P. J. Geology of mankind: the Anthropocene: Nature, v. 415, p. 23, 2002.

GADOTTI, M. Projeto político pedagógico da escola cidadã. In: Salto para o futuro: construindo a escola cidadã, projeto político-pedagógico. Secretaria de Educação a Distancia. Brasília: Ministério da Educação e do Desporto, SEED, 1998.

GUIMARÃES, R. P.; FONTOURA, Y. S. dos R. da. RIO+20 ou RIO-20? Crônica de um fracasso anunciado. Ambiente \& Sociedade, São Paulo, v. XV, n. 3, p. 19-39, set-dez, 2012.

GUIMARÃES, M. Pesquisa e processos formativos de educadores ambientais na radicalidade de uma crise civilizatória. Pesquisa em Educação Ambiental, vol.13, n.1, págs. 58-66, 2018.

IBGE - Instituto Brasileiro de Geografia e Estatística. Cidades@: Mossoró. Disponível em: https://cidades.ibge.gov.br/brasil/rn/mossoro/panorama. Acesso em: 02 out. 2020.

KLEIN, N. Isso muda tudo: capitalismo versus clima. London: Allen Lane, 2014.

LAYRARGUES, P. P. Apresentação: (Re)Conhecendo a Educação Ambiental brasileira. In: BRASIL. Ministério do Meio Ambiente. Diretoria de Educação Ambiental. Identidades da Educação Ambiental brasileira. Brasília: MMA, 2004. 
LAYRARGUES, P. P. Manifesto por uma Educação Ambiental indisciplinada. Ensino, Saúde e Ambiente, Número Especial, pp. 44-88, Junho, 2020.

LAYRARGUES, P. P.; LIMA, G. F. da C. As macrotendências políticopedagógicas da Educação Ambiental brasileira. Ambiente \& Sociedade, n.1, v.17, p. 23-40, 2014.

LIMA, E. S. Indagações sobre currículo: currículo e desenvolvimento humano. Brasília: Ministério da Educação, Secretaria de Educação Básica, 2007.

LIMA, G. F. da C. Crise ambiental, educação e cidadania: os desafios da sustentabilidade emancipatória. In: LOUREIRO, C. F. B.; LAYRARGUES, P. P.; CASTRO, R. S. (org.). Educação Ambiental: repensando o espaço da cidadania. São Paulo: Cortez, 2008.

LIMA, G. F. da C. Educação Ambiental no Brasil: formação, identidades e desafios. Campinas, SP: Papirus, 2011.

LIPIETZ, A. A ecologia política: solução para a crise da instância política? In: ALIMONDA, H. (Ed.). Ecologia política. Buenos Aires: CLACSO, 2002.

LOUREIRO, C. F. B. Educação Ambiental e movimentos sociais na construção da cidadania ecológica e planetária. In: LOUREIRO, C. F. B.; LAYRARGUES, P. P.; CASTRO, R. S. (org.). Educação Ambiental: repensando o espaço da cidadania. São Paulo: Cortez, 2008.

MARVILA, N. C.; GUISSO, L. F. Educação Ambiental e o processo de interdisciplinaridade no ambiente escolar. Revista Brasileira de Educação Ambiental (RevBEA), v. 14, n. 4, p. 340-350, 12 dez. 2019.

MELO, H. M. S.; CARVALHO, D. B.; SAMPAIO, D. B. Environmental Education and Sustainable Consumption: Teachers' Concepts and Practices. U. Porto Journal of Engineering, v.6, p.52-65, 2020.

MINAYO, M.C. de S. O desafio do conhecimento. São Paulo: Editora Hucitec, 2010.

MOORE, J. W. (Ed.). Anthropocene or Capitalocene? Nature, History, and the Crisis of Capitalism: PM Press, 2016.

MOREIRA, A. F. B.; CANDAU, V. M. Indagações sobre currículo: currículo, conhecimento e cultura. Brasília: Ministério da Educação, Secretaria de Educação Básica, 2008.

MORIN, E. Introdução ao pensamento complexo. Tradução de Eliane Lisboa. Porto Alegre: Sulina, 3ª Edição, 2007.

MORIN, E. A cabeça bem-feita: repensar a reforma, reformar o pensamento. Tradução Eloá Jacobina. 16ª ed. Rio de Janeiro: Bertrand Brasil, 2009.

OLIVEIRA, T. M. R. de; AMARAL, C. L. C. Ações para Minimizar a Fragmentação da Educação Ambiental em uma Escola Pública Paulista. Revista Brasileira de Educação Ambiental (RevBEA), v. 15, n. 3, p. 297-314, 27 maio 2020.. 
REIBELT, L. M.; RICHTER, T.; WAEBER, P. O.; RAKOTOARIMANANA, S.; MANTILLA-CONTRERAS, J. (2014) Environmental education in its infancy at Lake Alaotra, Madagascar. Madagascar Conservation \& Development, v.9, p.71-82.

ROCKSTRÖM, J. et al. Planetary boundaries: exploring the safe operating space for humanity. Ecology and Society, v. 14, n. 2, p. 32, 2009.

RODRIGUES, G. S.; PINTO, B. C. T.; FONSECA, L. C. de S.; MIRANDA, C. do C. O estado da arte das práticas didático-pedagógicas em Educação Ambiental (período de 2010 a 2017) na Revista Brasileira de Educação Ambiental. Revista Brasileira de Educação Ambiental (RevBEA), v. 14, n. 1, p. 9-28, 30 mar. 2019.

RODRIGUES, J. do N.; LOUREIRO, C. F. B. Pela formação integral de educadores: as dimensões reflexiva, crítica e ambiental. Educ. foco, Juiz de Fora, v. 22, n. 1, p. 1-25, 2017.

SANTOS, P. F.; DIAS, A. M.; COSENZA, A.; SILVA, M. A.; FONSECA, J. A. Impactos e Injustiças ambientais: significações de atores que constituem um conflito ambiental. Pesquisa em Educação Ambiental, vol.12, n.1, p. 100-114, 2017.

SAUVÉ, L. Uma cartografia das correntes em Educação Ambiental. In: Educação Ambiental: pesquisa e desafios. SATO, M.; CARVALHO, I. C. M. (org.). Porto Alegre: Artmed, 2005.

SOMMERMAN, A. Inter ou transdisciplinaridade?: da fragmentação disciplinar ao novo diálogo entre saberes. São Paulo: Paulus, 2006.

TEIXEIRA, G.; MARQUES, H.; OLIVEIRA, R.; COUTO, W.; FIREMAN, E. O silêncio sobre a Educação Ambiental nos cursos de Pedagogia das Universidades Federais do Brasil. Acta Brasiliensis, v.3, p.74-78, 2019.

TOZONI-REIS, M. F. de C.; CAMPOS, L. M. L. Educação Ambiental escolar, formação humana e formação de professores: articulações necessárias. Educar em Revista, Curitiba, Brasil, p. 145-162, Edição Especial n. 3, p. 145162, 2014.

TRAJBER, R.; MENDONÇA, P. R. (org.). Educação na diversidade: o que fazem as escolas que dizem que fazem Educação Ambiental. Brasília: Secretaria de Educação Continuada, Alfabetização e Diversidade, 2007.

VIEGAS, P. de L.; NEIMAN, Z. A prática de Educação Ambiental no âmbito do ensino formal: estudos publicados em revistas acadêmicas brasileiras. Pesquisa em Educação Ambiental, vol. 10, n. 2, págs. 45-62, 2015. 